\title{
Live (Life) Streaming: Virtual Interaction, Virtual Proximity, and Streaming Everyday Life during the COVID- 19 Pandemic
}

\author{
Ujjwal Khobra ${ }^{1} \&$ Rashmi Gaur ${ }^{2}$ \\ ${ }^{1}$ Doctoral Student, Department of Humanities and Social Sciences, Indian Institute of \\ Technology Roorkee, Roorkee, Uttarakhand-247667.singh.ujjwal1994@gmail.com, \\ ukhobra@hs.iitr.ac.in, https://orcid.org/oooo-ooo2-5271-3518. \\ ${ }^{2}$ Professor, Department of Humanities and Social Sciences, Indian Institute of Technology \\ Roorkee, Roorkee, Uttarakhand-247667, rashmigaur@hs.iitr.ac.in
}

\begin{abstract}
This paper proposes to examine the digital event of live streaming as an entanglement of digital engagement, virtual proximity, and virtual embodiment as a possible posthuman concern, foregrounded by the ongoing COVID- 19 pandemic. The transition witnessed in the medium of communication between humans has significantly deconstructed our understanding of the 'normal', consequently introducing a new phase of lost corporeality, digitally. Unforeseen excessive employment of the virtual engagement system of live (life) streaming is a testament to the current human extremity. In the light of this transition, the paper attempts to explore the possibility of witnessing some semblance of reality by altering the praxis of normalcy in the practice of the COVID appropriate 'new normal' through the virtual medium of a live stream. Since the ontology of human exceptionalism has come under direct attack due to the current pandemic, a reassessment of the human/ technology interphase and its consequent posthuman predicament is urgent. Drawing on Rosi Braidotti's concept of life beyond the self and N. Katherine Hayles's concept of embodied virtuality, this paper analyses the technical feature of live streaming as the 'digital' becoming of human beings in the contemporary COVID- 19 world, further complicating the modes of construction of embodiment through live (life) streaming.
\end{abstract}

KEYWORDS: COVID- 19, pandemic, live streaming, virtual proximity, virtual interaction, new normal, virtual embodiment, posthuman.

\section{Introduction: Contestations and Paradoxes}

Ihab Hassan, in his remarkable article, "Prometheus as Performer: Towards a Posthumanist Culture? A University Masque in Five Scenes" (1977) "helplessly" witnessed the emergence of the posthumanist thought in the literary circle and admonished the academe to revisit the premature category of the 'human' and its essential characteristics to understand the altercations present in the discourse of human thought and the exceptionalism propounded by the designed human form and humanity in its entirety (Hassan 1997). On revisiting Hassan's observation, the ongoing COVID- 19 pandemic appears to be a rupture in the epistemological assessment of what it means to be human during the pandemic and the challenges faced by humanities as a discipline to constitute meaning beyond and across the structural paradigms of being human. The fear of the contagious virus, the non- human other has forced us to deploy the 'post'-narrative to rationalize our contemporary quarantined existence. The human body operating in the current COVID-19

(C) AesthetixMS 2020. This Open Access article is published under a Creative Commons Attribution Non-Commercial 4.o International License (http://creativecommons.org/licenses/by-nc/4.o/), which permits non-commercial re-use, distribution, and reproduction in any medium, provided the original work is properly cited. For citation use the DOI. For commercial re-use, please contact editor@rupkatha.com. 
ecosystem is one of the nth permutations of the posthuman pedagogy and thus the cartographic objective is to understand the restrictive yet creative functionality of the human body to articulate its survival, suffering, and the 'digital' becoming through the technical feature of live streaming. However, the digital mode of articulation produces a monumental corpus of developments in the framework of the posthuman (Balsamo 1996; Hayles 1999; Badmington 2000; Braidotti 2006). The bare process of determining our current crises engenders a barrage of unsettling questions and propositions: What does it mean to be a human in the present COVID-19 world? Can we define our act of survival as an evolutionary endgame, philosophically? What role does technology play in the course of digital engagement and virtual embodiment in this time of social distancing? Despite such uncertainties, we have created a 'new normal'. From claustrophobic containment to excessive sanitization, virtual commotion to physical stagnancy, experiencing angst to celebrating resilience (online), the outbreak of the pandemic has manufactured idiomatic spatial affectations in human bodies. In addition to this deduction, the aim is to foray into this concatenation of contained virtual performance, lived COVID-19 infected reality and the apparent fear induced by the non- human virus as 'COVID(ien) signifiers' rather than a methodological assessment of our current collective state of immobile existence.

In speaking through the pandemic, the (post) human imaginary of the dystopian ecosystem is our present locus, therefore we need to revisit the ideals of sustenance both collectively and individually. Since the theatricality of the homely body is observed through a virtual medium, this paper focuses on the digital situatedness of the human body in the times of COVID- 19, intrinsically, through the event of live streaming and subsequent digital performance of the everyday uncanny. The technical feature of live streaming registers our everyday strangeness in the form of digital archives and simultaneously captures a plurality of subjectivities (experiences and affect) in and under containment. The prerequisite for quarantine is the accessibility, affordability, and availability of a safe space, and the praxis of privilege remains a constant variable. While performing and organizing the virtual community on a live stream, the disembodied virtual subjectivity of an individual is confronted with the question of virtuality. A condition where technologies determine sense, orientation, and articulation in the form of codes, symbols, and information. More specifically, “...a way of understanding ourselves as embodied creatures living within and through embodied worlds and embodied words"( Hayles 1999).

In this regard, we have advanced from demonstrating solidarity (online) to a more destabilized sense of the (virtual) embodiment. Who are we when we are digital codes in a live stream? The fear of the non- human other (virus) and the fundamental concern of survival has devolved us into virtual codes as technologized other, distinguished from the isolated corporeal self. The acceptance of bodiless virtuality in the form of virtual engagement is an attempt to map the narrative of resistance which presents multiple (post) human contestations (Hayles 1999). Since the movement is beyond the bodily constraints, the posthuman can detect the violence posed by the non- human other and we can rationalize our state of being human and the enlarged spectrum of inhumanity foregrounded by the current adversity. Isolation and the restrictive practice of quarantine has transformed our understanding of survival and the COVID(ien) stagnancy is expressed via virtual performance in an unedited live stream. Therefore, the representation of stagnancy can be registered as a posthuman motif in the course of virtual disembodiment (Badmington 2000; Balsamo 1996; Braidotti 2006; Graham 2002; Gray 1995; Haraway 1991; Hayles 1999; Zylinska 2002; Sharon 2012). 


\section{Live (Life) under Containment and the Posthuman}

Amidst the psychotic vulnerabilities experienced by individuals, globally as an outcome of the rapid escalation of the COVID-19 pandemic, the feeling of isolation and variegated other helplessness dominate the psyche of the individual under self-quarantine. We have become prisoners of familiarity. The practice of self- isolation, safe distancing, restricted mobility posit an incursion into radically transformed spaces that we routinely inhabit ( a room, a house, a corner, or the literal mindscape of intimate aspirations). A somber heart, a dismal performance of mundane chores, an opaque accumulation of passing time envelops our dermis and we ensure our survival. The liminal mode of COVID(ien) existence has transpired a paradigmatic inquiry into the discursive practice of practicing restriction which can be helplessly termed as an 'abundance of spatial familiarity' with posthuman experientiality. The contained body is a site of grotesque and survival. However, the prominence of the former allows self- reflexivity, a performance without the scope and desire of engagement, a quasi- emotional emission of excremental superficiality, a deliberate cleansing of thought and action, an unedited display of misery ensures life under containment. This forms a possible site of theorization for the posthuman, philosophically. However, the posthuman can function as a theoretical apparatus and a measure of analytical inquiry in the form of human and non- human hybridization or "coupling" (Pickering 2005). The medical coupling of the human and the non- human contagion produces a systematic dismantling of the perceived certainty of human supremacy over other life forms. This hybridization has created affects of "othering" and the otherness is organized as (non- infected bodies and infected bodies), where the exclusionary politics operate with the fundamentals of fear and a perpetual state of anxiety. The status assigned to infected bodies evoke fear. We are "constructing" new bodies with the counter logic of negation and "othering" as pejoration (Braidotti 2013). However, the process of othering haunts digital narratives because the scientific narrative is part of the cultural narrative within and across the posthuman culture (Hayles 1999). For instance, the consumption of live streams is emblematic of the human pursuit to find assemblage and avoid the possibility of isolation, if not exile. The preventive measures exercised to stay safe are practical applications exhibited by humans to possibly restrict contact with the contagion. A COVID appropriate virtual performance featured in a live stream presents an altered phantasm of the outside world and recurrent digitalization of the domestic space. The virtual space created through virtual interaction and engagement is an appropriate depiction of a digital utopia under lockdown. Yet, this particular mode of communication via a live stream denotes a system of privilege and cannot be read in isolation which can also translate into a possible departure from reality, evoking dystopic countercurrents. Here, we recognize the other as a technologized entity, performing in the domestic setup, aware of the digital screen, simultaneously evoking technophilia and technophobia. The current posthuman predicament presents another ideological construction in the form of endangerment. By subtracting the possibility of any form of physical assembly, can we be human enough? The etymological revisitation of the term 'quarantine' presents a discursive divide in performance and performing. On one hand, we perform quarantine and on the other, the performance is marked by the state of containment. Therefore, the extent of exploration is unfathomable yet stained by a varied degree of subjectivities at play, marked by a movement towards digital metanarratives (Hayles 1999).

\section{Virtual Intimacy and Virtual Engagement}

The discourse of posthumanism and the posthuman body has found widespread acknowledgment and meditations due to the ongoing pandemic. The current quarantined state of the human body acts as a literary intersection for research in technology, medical science, and humanities. The 
physiological state of possible temporary stasis does not restrict an individual's virtual mobility. Therefore, the aim is not to arrive at profound conclusions (endings) but perhaps make sense of our current maladjusted subjectivity under isolation. The production of multimedia modalities in the form of virtual engagement in a live stream has transformed the formulaic experience of performing everyday rituals. Live Streaming as a technical feature promotes the unfiltered, unedited, direct flow of information in real-time, and the virtual chat rooms are essential promotional subsets. The explosion of live streams on various digital platforms has augmented user-specific virtual engagement. However, the technologized virtual body is an appropriate representation of phobogenic aesthetics of cultural production in the times of COVID- 19. The false illusions of intimacy experienced by an individual on a live stream and in a virtual chat room is a result of virtual engagement contextualized by performance in a contained landscape with ever advancing mindscape. Yet, we have designed a new way to interact, engage, and associate with people through a live stream due to COVID- 19 pandemic with (post) human casualties.

Since the paradigms of physical proximity have changed the way we register interactions and engagements with people, the addition of virtual space has created absolute demarcations of disembodiment with unlimited association with "virtuality" (Hayles 1999). We are already technologized. Our everyday life is relentlessly shaped by technology and the continuous production of stories, events, narratives is determined by the usage of technology. Such narratives shape our understanding of society and culture and to a major extent our cognition and behavior. These narratives are loaded receptacles of technology- culture intersectionality and the feature of live streaming is an example of such intersection. The act of becoming 'digital' is a function of necessity rather than desirability: the desire to keep in touch, be updated on the latest information, learn a new skill to maintain the illusion of productivity, be a passive viewer, form virtual groups to demonstrate solidarity, and develop a system of support, thus amplifying psychosocial implications. An array of heteroglossic digital codes and the polyphonic existence of the virtual audience combined with virtual interaction denounces the singularity of thought, action, and medium. To explicate the consequential shift in advancing assumptions about virtual proximity symptomatic of the current posthuman predicament, we can perceive the digital event of live streaming as a literary text. The event of live streaming produces a system of narrativized information of subjectivity and a virtual pool of empathy. The virtual manifestation of reformed subjectivities and the exhausting meditations on productivity have spammed the online feed. With this eccentric performance of virtual entourage at play on a live stream, the next mammoth task is to determine the realignment of a niche literary space created by the intersection of the posthuman and the COVID(ien) tangents of normalcy and physical distancing measures adopted by individuals under lockdown.

Interestingly, the event of live streaming provides a comprehensive acknowledgment of our current situation and attests testimonial progression towards recombinant (post) humanism. The virtual nature of the live stream acts as a 'literary text' which plays a crucial role in the progression of the posthuman narrative (Hayles 1999). Hayle's How We Became Posthuman posits this technological implication as:

Literary texts are not, of course, merely passive conduits. They actively shape what the technologies mean and what the scientific theories signify in cultural contexts..........., culture circulates through science no less than science circulates through culture. The heart that keeps this circulatory system flowing is narrative- narratives about culture, narratives within culture, narratives about science, narratives within science." ( Hayles 1999) 
The virtual narratives produced via live streams in the form of virtual engagement with human bodies as digital codes determine the liminality of incarcerated spaces, a proxy performance of being alive in a live stream. The use of technology (habitual, essential, unquestioning, seamless) has constructed and contributed to this specific "human experience" and the human-technology interface formulates such epistemological conjectures. This "experience" is "a fiction and a fact" (Haraway 1991). Such narrative is constructed via excessive employment of the virtual engagement system of live (life) streaming: an outcome of the fear of mortality rather than the fear of sudden death because survival is an intersubjective epithet, borrowing means of 'being' rather than 'becoming' human.

In considering the ongoing adversity, a literary study of live streaming: as an attempt to derive some preliminary observations and provide context to the convoluted assemblage of virtual engagement, virtual embodiment, and virtual proximity is marked by a rupture in the literary rubric of the (post) human dictums, theory, and practice. Here, the possibility of defining such systems of information is a complex measure of exercising caution and restraint because the (post) COVID scenario is yet to emerge. We can, however, provide an adequate response to algorithms and codes of live streaming arrested by this absurdist debasement of values assigned to non- virtual beings. However, the committal affordance of calibrating distance through virtual engagement on a live stream has already algorithmized our current misery. The privileged virtual practice of streaming live demonstrates the human/ technology interface following human survival in response to the viral contagion and this necessary self-divestment of physical association accommodates the posthuman.

\section{Towards a New Normal}

According to N. Katherine Hayles, "The posthuman subject is an amalgam, a collection of heterogeneous compounds, a material- informational entity whose boundaries undergo continuous construction and reconstruction" (Hayles 1999). However, the advent of the COVID19 pandemic has exposed man's inability to comprehend limitations and the ontological "decentering of the human"( Badmington 2000; Balsamo 1996; Braidotti 2006; Graham 2002; Gray 1995; Haraway 1991; Hayles 1999; Zylinska 2002; Sharon 2012). The incubation period of the viral pandemic will determine and influence the fate of COVID- 19 (COVID(ien)) literature, hence "continuous construction and reconstruction" of the posthuman pedagogy is mandatory (Hayles 1999). However, surviving the pandemic and writing about the current situation leaves us in a state of flux, a contained limbo. A brief summarization of the futile labor of demonstrating incarcerated everyday spaces may result in an acknowledgment of the ongoing adversity and possibly generate illusions of assembly through virtual simulations but cannot yet find substantial answers to the effective ruptures in the epistemological understanding of the (post) human, ironically. The unprecedented transformation of the pre-COVID normalcy has launched a philosophical mediation that remains deeply embedded in the practice of survival and encourage a movement towards the 'new normal'. Yet, the 'new normal' is characterized by the privilege of accessibility, affordance (virtual and economic), a plurality of contained subjectivities, and debris of the inconsequential other (contagious bodies). However, the socio-normative discourses on participation, articulation, and innovation are malleable functions of the digital networks and scientific narratives within a culture (Hayles 1999, Balsamo 1996). The propensity of incommensurable views on human subjectivity cannot be necessarily collected via digital codes on a live stream. Yet, we need to move beyond and across the etymology of quarantine and continue to speak through the pandemic until we reach a (post) COVID narrative. 


\section{References}

Badmington, Neil. (Ed.) (2000). Posthumanism. New York: Palgrave.

Balsamo, Anne. (1996). Technologies of the Gendered Body: Reading Cyborg Women. Durham and London: Duke University Press.

Braidotti, Rosi. (2006). Transpositions: On Nomadic Ethics. Cambridge: Polity Press.

Braidotti, Rosi. (2013). The Posthuman. Cambridge Polity Press.

Haraway, Donna. (1991). 'A Cyborg Manifesto: Science, Technology, and Socialist-Feminism in the Late Twentieth Century', pp. 149-181, in, Simians, Cyborgs and Women: The reinvention of Nature. New York: Routledge.

Hassan, Ihab. "Prometheus as Performer: Toward a Posthumanist Culture?" Performance in Postmodern Culture, vol.31, no. 4, April 1977, 830-85o, https://www.jstor.org/stable/41397536. Accessed: $17 / 05 / 2020$.

Hayles, N. Katherine. (1999). How We Became Posthuman: Virtual Bodies in Cybernetics, Literature, and Informatics. The University of Chicago Press.

Hayles, N. Katherine. (2005). 'Computing the Human', Theory, Culture, and Society. 22(1): 131-151.

Graham, Elaine. (2002). Representations of the Post/Human: Monsters, Aliens, and Others in Popular Culture. New Brunswick, N.J.: Rutgers University Press.

Gray, Chris. H. (Ed.) (1995). The Cyborg Handbook. New York: Routledge.

Ujjwal Khobra is currently pursuing her Ph.D. from the Department of Humanities and Social Sciences, Indian Institute of Technology Roorkee in Posthuman Studies and Literature and Science Studies. She completed her B.A. in English Literature from the University of Delhi and earned her M.A. in English Literature from the Department of English, University of Delhi. Her areas of interest include Digital Humanities, Women and Gender Studies, Posthuman Studies, and the Anthropocene. She has also participated in several workshops and conferences in India.

Rashmi Gaur is a Professor of English, she teaches courses in Communication, Culture, Gender Studies and Media (Film and Literature) at the Indian Institute of Technology Roorkee. In her career, spanning three decades, she has guided about 12 Ph.D. theses. She has published four books, also to her credit there are more than ninety research papers in national and international journals. Besides, she has traveled extensively and has participated in many conferences in India and abroad. She also runs consultancy projects in related areas. She is a member of several academic bodies. At present, she is working in the area of Media, Digital Humanities, and Professional Communication. 